\title{
EL ÁLBUM FOTOGRÁFICO DE MARTÍN LUIS GUZMÁN PARA LAS FIESTAS DE LA CONSUMACIÓN DE LA INDEPENDENCIA EN MÉXICO EN 1921
}

Ma. de las Nieves Rodríguez y Méndez*

\author{
MARTíN LUIS GUZMÁN's PHOTO ALBUM \\ CHRONICLING THE 1921 MEXICAN \\ INDEPENDENCE FESTIVITIES
}

RESUMEN: Las fiestas del Centenario de la Independencia de 1921 fueron de gran importancia en México. Durante el mes de septiembre, bajo la mirada de embajadores y delegados extranjeros, se celebró y mostró al país como una nación estable y pacífica. El álbum fotográfico de Martín Luis Guzmán fue la crónica visual de ese mes, de los festejos, la sociedad y la aceptación del pueblo del primer gobierno posrevolucionario e institucional.

PALABRAS CLAVE: Álvaro Obregón, Revolución Mexicana, Centenario, Guerra de Independencia, Martín Luis Guzmán.
The festivities of the Centenary of Independence of 1921 were highly significant in Mexico. During the month of September, celebrations were held in the presence of ambassadors and foreign dignitaries, presenting the country as a stable and peaceful nation. Martín Luis Guzmán's photographic album was a visual chronicle of that month's festivities, the society, and people's acceptance of the first post revolutionary and institutional government.

KEYWORDS: Álvaro Obregón, Mexican Revolution, Centenary, Independence War, Martín Luis Guzmán.

* Licenciada y maestra en Historia del Arte por la Universidad Nacional Autónoma de México. 


\author{
EL ÁLBUM FOTOGRÁFICO \\ DE MARTÍN LUIS GUZMÁN PARA \\ LAS FIESTAS DE LA CONSUMACIÓN \\ DE LA INDEPENDENCIA \\ EN MÉXICO EN 1921
}

Cadr ada sociedad inventa su propia memoria y es a través de las celebraciones que escoge conscientemente qué sucesos o personajes retomar como concreción de los ideales de la nueva nación moderna. Estas naciones, limitadas y soberanas, se imaginan a sí mismas como comunidades plurales, asentadas tras un período de guerras sobre la memoria de una fraternidad que los asume dentro de una determinada sociedad. La celebración de los festejos del Centenario de la Independencia fueron una muestra exultante de la visión estatal de la memoria nacional. Durante el Porfiriato la memoria fue utilizada como una "conmemoración política y discurso histórico, así como para organizar las referencias al pasado en función de los imperativos del poder". Mientras que en la celebración de 1921 esta memoria autoritaria cedió su lugar a "una nueva que ya no pasaría por el discurso histórico, sino que abordaría el pasado con enfoques cultural, antropológico y arqueológico". ${ }^{1}$ Fue así, como apunta Lempérière, que tras la crisis porfirista y el movimiento armado la memoria histórica del nuevo régimen posrevolucionario encontró en el relativismo cultural una nueva forma de sensibilidad histórica.

Monumentos y celebraciones, como expresión de la sensibilidad histórica de su tiempo, funcionaron como una afirmación del poder presente contri-

${ }^{1}$ Annick Lempérière, "Los dos centenarios de la Independencia Mexicana (1910-1921): De la historia patria a la antropología cultural”, Historia Mexicana, 178 (2), México, 1995, pp. 318-9. 
buyendo a definir la relación de las colectividades con su pasado y la consecuente construcción de su memoria histórica al atribuir a los nuevos espacios un sentido comunitario. Estas prácticas ejercían una transmisión de la memoria a través de la rememorización del discurso oficializado mediante los festejos, la obra pública y la difusión de los libros y álbumes que circularon profusamente en el primer tercio del siglo XX. Estos trataban de "definir y reforzar sentimientos de pertenencia, que apuntan a mantener la cohesión social y a defender fronteras simbólicas [expresadas en] narrativas canónicas oficiales que se difunden en los textos de Historia". ${ }^{2}$ Así, la memoria se convierte en una religión civil que debía ser mantenida por el Estado y rescatada en el marco de las celebraciones como un baluarte fundamental de construcción de la nación. La nación, entendida como "una comunidad política imaginada como inherentemente limitada y soberana" 3 donde los ciudadanos son capaces de imaginarse en un contexto social colectivo que se concretaría en las fiestas patrias.

De acuerdo con Paul Ricoeur, la historia institucional presentaba dos componentes: por una parte un significante cognitivo en el cual debíamos preguntarnos qué se recuerda y, por la otra, uno pragmático en el que preguntamos cómo se recuerda. ${ }^{4}$ Partiendo de la base de que el pasado está ligado inexorablemente a una imagen ideológica del mismo podría decirse que entonces la memoria quedaría vinculada con la imaginación que podía limitarla en algún momento. Si, como Pascal, sujetamos la condición imaginativa a un estrato básico del saber, adheriríamos el concepto de la imaginación a un mundo fenomenológico externo de tal manera que sumergiríamos en la confusión los conceptos de rememoración e imaginación comprometiendo la función veritativa de la memoria. En las celebraciones del Centenario y las diversas representaciones fotográficas que se difundieron se reivindicó la imaginación por medio de lo fantástico y lo irreal (desfiles, rememoración de los tiempos históricos pasados) a través del desarrollo de un programa sujeto a la memoria que, paradójicamente, estaba en la búsqueda de la verdad a través de una fenomenología de los fragmentos necesariamente sujetos al entendimiento propio de la Historia en cada una de las etapas en la que fue celebrado.

En el Centenario de 1910 el gobierno porfirista celebró la conmemoración mediante un derroche de recursos que sirvió también para mostrar un país

\footnotetext{
${ }^{2}$ Elizabeth Jelin, Los trabajos de la memoria, Madrid, 2002, pp. 40-1.

${ }^{3}$ Benedict Anderson, Comunidades imaginadas. Reflexiones sobre el origen y la difusión del nacionalismo, México, 1993, p. 23.

${ }^{4}$ Apud Paul Ricoeur, La memoria, la historia, el olvido, México, 2004.
} 
NOTAS

moderno que difundía su particular visión de la historia. En el álbum México en el centenario de la Independencia publicado por Eugenio Espino se retrató fotográficamente un país que comenzaba a "marchar rápidamente hacia el progreso, hasta llegar a la altura que aquí se ve". ${ }^{5}$ Estos festejos, previstos desde 1907, estuvieron a cargo de una Comisión Nacional que debía organizar cuidadosamente la conmemoración. ${ }^{6}$ Ramón Corral, como presidente de dicha comisión, informó personalmente a Guillermo de Landa y Escandón, Gobernador del Distrito Federal, la decisión de nombrar una Comisión para organizar los festejos. Fueron designados como vocales Francisco D. Barroso, Serapión Fernández, Rómulo Pasquel, Fernando Pimentel y Fagoaga, Eugenio Rascón, Rafael Rebollar, Carlos Rivas, Manuel Vásquez Tagle y como secretario José Casarín. ${ }^{7}$ Se reunieron un total de 70 veces durante tres años con el fin de nombrar las subcomisiones capaces de manejar los recursos para financiar el programa que se desarrollaría en cada uno de los estados de la República.

El modelo de celebración para la conmemoración tuvo sus antecedentes en la celebración del centenario del natalicio de Benito Juárez y en la instalación del pabellón mexicano en la Exposición Universal de París de 1889. Annick Lempérière indica también que la Comisión se basó en el modelo de celebración francés de 1889, en el que la asociación entre la exaltación de la memoria histórica y la proyección del progreso se realizó con una dimensión internacional que el gobierno confirió al invitar a participar a las distintas delegaciones diplomáticas. Al pueblo se le "ofreció la unidad negada a tra198 vés de un período festivo que otorgaba la suspensión de las reglas y colocaba a sus asistentes fuera de las condiciones ordinarias de la vida. Algunos lo tomaron como el ejemplo más refinado del patriarcado porfirista; otros, la mayoría de los mexicanos, como el reflejo de sí mismos en su propia esencia. Esta fiesta produjo un ensanchamiento del campo de la conciencia; expandió y amplificó la vida del mexicano participante que intuía un cambio, que reconocía sus barreras [y] sus autocontroles". ${ }^{8}$

${ }^{5}$ Eugenio Espino, México en el centenario de la Independencia, México, 1910, p. 5.

${ }^{6}$ Cfr. Memoria de los trabajos emprendidos y llevados a cabo por la Comisión Nacional del Centenario de la Independencia designada por el Presidente de la República el 1 de abril de 1907, México, 1910.

${ }^{7}$ Manuel Vázquez Tagle renunció y fue sustituido en su puesto por Porfirio Parra, así como también Francisco D. Barroso, Serapión Fernández y Pedro Rincón Gallardo tuvieron que ser sustituidos por Ignacio Burgoa, Agustín Lazo y Porfirio Díaz hijo, debido a su fallecimiento durante el proceso. De igual forma cabe advertir que los liberales doctrinarios no fueron llamados a participar de la Comisión para la organización de los festejos y por ello mostraron su inconformidad saboteando algunas de las celebraciones o rehusándose de acudir a las procesiones cívicas y desfiles organizados para la conmemoración.

${ }^{8}$ Zurián, Carla, "Noticias oficiales y crónicas incómodas: la prensa durante las Fiestas del Centenario (1910-1921)", en <http:// historiadoresdelaprensa.com.mx/hdp/files/256.pdf>, consultado el 4 de enero de 2015, p. 4. 
De tal grado fue la celebración que abarcó, entre otros actos, la inauguración de la Universidad Nacional, del Manicomio General -conocido popularmente como "La Castañeda"-, de la Escuela Normal Primaria para Maestros, del Hemiciclo a don Benito Juárez y de la Columna de la Independencia ${ }^{9}$ a la que tan solo quince años después llevarían los restos de los héroes resguardados hasta entonces en la Catedral metropolitana. La festividad pronto hubo de suponer la despedida del régimen imperante. ${ }^{10}$ Todo parecía indicar que el estado de bonanza vivido hasta entonces se desmoronaba ante la crisis que atravesaba la nación y que desencadenó, tan solo un mes después, la Revolución mexicana. ${ }^{11}$

Con la llegada de Álvaro Obregón al poder presidencial se puso fin a más de una década de enfrentamiento armado. Este, como gobernante que emergió de la contienda, ejerció un poder centralizado que fue considerado legítimo al estar apoyado en el sector popular. Fue durante su presidencia (1920-1924) que se sentaron las bases del nuevo Estado mexicano que habría de cohesionar las fuentes políticas y sociales del país que dieron como resultado un Estado autoritario pero legítimo que fomentó las bases para la formación de las distintas instituciones que habrían de regir la nación y el sentimiento nacionalista.

"La promesa de un verdadero gobierno, en manos del caudillo Álvaro Obregón, era atractiva para el imaginario colectivo, porque el único poder real era el suyo, con todas sus alianzas y su legitimidad. Obregón realizaría a plenitud el papel que su destino personal le deparaba, que era el de ser caudillo -el último- de México". ${ }^{12}$ Fue de ese modo que construyó Álvaro Obregón y, posteriormente, su sucesor Plutarco Elías Calles una nueva idea de Estado nación que entendió el concepto esencial de la Revolución para asentar las bases de un nuevo Estado moderno valiéndose de grupos que lo-

9 “México Artístico. El nuevo Palacio de Comunicaciones es una obra magnífica”, El Imparcial, México, 1910, p. 11.

${ }^{10}$ Este hecho encontró su referente profético en el paso del cometa Halley en el mes de mayo de 1910, quedando registrado en las distintas zincografias de José Guadalupe Posada, quien hizo eco en "La llegada del cometa", "El cometa del Centenario de la Independencia. 1810-México-1910", "Dialoguito de Mamá Tierra con D. Cometa Halley" y "El Centenario de la Independencia de México en el año de 1910”. En las obras realizadas en honor a los héroes patrios, se muestra un claro desdén hacia los festejos del régimen porfiriano así como también hacia la figura del presidente la cual desdibuja en el horizonte en pro de la representación de Madero que, cual cometa, viene cayendo irremediablemente sobre la ciudad.

Cfr. María de las Nieves Rodríguez y Méndez, "La celebración del Centenario de la Independencia de México en 1910 a través de algunos grabados de José Guadalupe Posada", Takwá. Revista de Historia, 5, México, 2007, pp. 157-72.

${ }^{11}$ Apud José Ma. Luján (pról.), Entrevista Díaz-Creelman, México, 1963.

${ }^{12}$ Pedro Castro, “Álvaro Obregón, el último caudillo", Polis, 2 (3), pp. 209-229. 
NOTAS

graron desempeñar el papel crítico más representativo de esta construcción: maestros, líderes e intelectuales que surgieron del movimiento nacional popular y cuya contribución artística y social fue incalculable. ${ }^{13}$

En el año de 1921 se conmemoró el centenario de la consumación de la Independencia mexicana. Los festejos estuvieron organizados por un Comité Ejecutivo conformado por Emiliano López Figueroa como presidente, Juan de Dios Bojórquez como vicepresidente, Martín Luis Guzmán como Secretario y Carlos Argüelles como tesorero. ${ }^{14}$ Juntos debían realizar el programa oficial de los festejos que, presididos por el General Obregón, debían llevarse a cabo durante el mes de septiembre de ese mismo año. Asimismo, se contó con la colaboración de algunas instituciones privadas como el periódico El Universal, la Compañía Independiente de Luz y Fuerza, la Universidad Nacional de México y el diario Excélsior, entre otras, que participaron realizando eventos y actos de carácter popular. ${ }^{15}$

Los actos ofrecieron una variedad de actividades y espectáculos que deleitaron a los habitantes durante todo el mes: el desfile de carros alegóricos, el festival floral en Xochimilco, varios concursos de corte literario y musical donde se eligió el Himno y el Poeta del Centenario, la inauguración del conjunto de la Ciudadela en Teotihuacán y el paseo en coche para niños pobres. ${ }^{16}$ La revitalización de la figura del indígena como imagen estereotípica del pueblo y la muestra de la magnificencia con que la patria resurgía tras el triunfo revolucionario fueron los bastiones del imaginario que se comenzaba a difundir a través de actos como este; la exposición itinerante de arte popular (organizada por Gerardo Murillo, Dr. Atl, Jorge Enciso y Roberto Montenegro) que tuvo como fin rescatar y exaltar la artesanía popular mexicana ${ }^{17}$ y la celebración en el Bosque de Chapultepec de la Noche

${ }^{13}$ El descubrimiento de gran parte de los monumentos prehispánicos de Teotihuacan vitalizó la tradición indigenista en el país, a la cual se sumaban los esfuerzos de crear un lenguaje pictórico nacional que recuperase esta tradición y, al mismo tiempo, configurase el imaginario nacional mexicano. Fue por esto que se divulgó como parte del programa curricular de primaria el método de dibujo de Adolfo Best Maugard con el que se pretendería despertar en el mexicano el sentido más puro de la gráfica indígena. José Vasconcelos, como Secretario de Educación, comenzó a desarrollar programas de alfabetización de indígenas para lo que se comisionarían maestros rurales que serían enviados a toda la república.

${ }^{14}$ Cfr. Programa Oficial de las Fiestas del Centenario de la Consumación de la Independencia de México, México, La Helvetia, 1921.

15 "El pueblo tendrá acceso a todas las fiestas del Centenario", El Universal, México, 2 de junio de 1921, p. 1.

${ }^{16}$ Clementina Díaz y de Ovando, "Las fiestas del 'Año del Centenario': 1921”, México: independencia y soberanía, México, Secretaría de Gobernación, Archivo General de la Nación, 1996, p. 110.

${ }^{17}$ Cfr. S. Suárez Longoria, "La exposición de arte popular", Azulejos, México, octubre de 1921, pp. 28-30. 
Mexicana, ${ }^{18}$ organizada por Adolfo Best Maugard, en la cual participaron de la modernidad de un Estado que quiso celebrar su centenario de modo "esencialmente popular".

\section{FIGURA 1}

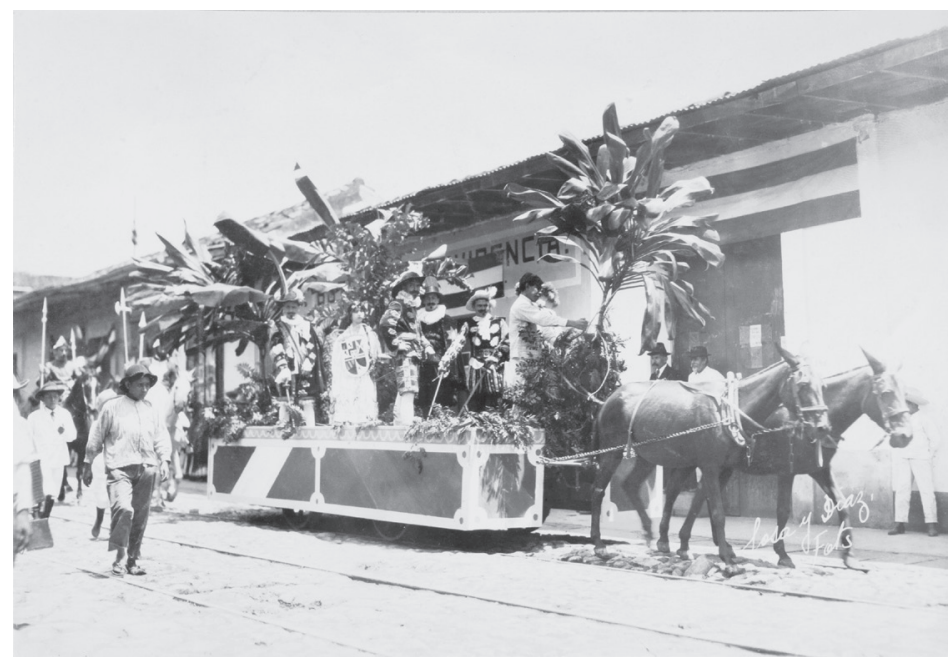

Paseo en auto para los niños pobres, ciudad de México, 1921.

Archivo Histórico de la Universidad Nacional Autónoma de México, Centro de Estudios sobre la Universidad, Fondo Martín Luis Guzmán, Álbum fotográfico de Martín Luis Guzmán.

\section{El álbum particular de Martín Luis Guzmán}

En el rescate de la memoria histórica como parte de las actividades que se llevaron a cabo alrededor de los festejos del Bicentenario, se recuperó el álbum elaborado por Martín Luis Guzmán (1887-1976) en 1921. ${ }^{19}$ Este álbum, de carácter privado, se tornó de gran importancia al ofrecer la visión popular de los festejos por parte de uno de sus organizadores.

Martín Luis Guzmán estuvo ligado al movimiento revolucionario mexicano, militando primero al lado de Francisco I. Madero para luego unirse a la

${ }^{18}$ María de las Nieves Rodríguez y Méndez, “La 'Noche Mexicana' como parte de los festejos de celebración de la Independencia de 1921”, Estudios. Filosofía. Historia. Letras, XI (105), México, ITAM, 2013, pp. 57-71.

${ }^{19} \mathrm{El}$ álbum se encuentra en el fondo homónimo del Centro de Estudios Sobre la Universidad de la Universidad Nacional Autónoma de México. 
facción villista en su Chihuahua natal. Esta aventura lo llevó a retratar como nadie la cruel realidad de un México convulso y acaudillado que se sucedió en la primera década del siglo XX en sus novelas y que le ganó el Premio Nacional de Literatura en 1958. Hasta el año de 1920 residió en los Estados Unidos, donde trabajó activamente como periodista llegando a publicar y a colaborar en publicaciones de tiraje nacional como El Universal. Fue a su regreso a México cuando publicó dos de sus obras fundamentales, El águila y la serpiente (1928) y La sombra del caudillo (1929), que reflejó la crisis política que había vivido el país durante la contienda armada.

Martín Luis Guzmán vivió las celebraciones centenarias de modo contrapuesto. En 1910, él -aún parte del Ateneo de la Juventud- se enfrentó a una realidad dividida entre la crisis sustancial del país y los festejos del gobierno porfiriano; y, en 1921, como representante de la Secretaría de Relaciones Exteriores fue designado miembro del Comité Organizador de los festejos. Fue en este momento en que se inmiscuyó en las celebraciones del Centenario y, en su afán de cronista, adquirió un registro fotográfico de los acontecimientos. Estos documentos se convirtieron en parte fundamental de la memoria histórica que tanto los individuos como la nación quisieron rescatar como parte de la legitimación del nuevo Estado emergente y superviviente a la lucha armada revolucionaria.

El álbum (compuesto por 1009 fotografías) se circunscribió a una necesidad de historiar que iba más allá del mero registro familiar que tanta fascinación producía entre las clases pudientes de la época. ${ }^{20}$ Debe analizarse como la crónica gráfica de los propios festejos que seguía cronológicamente el programa de actos oficial. El carácter narrativo se dejaba advertir desde las primeras páginas del álbum, ${ }^{21}$ el cual daba inicio con los héroes de la Independencia: Miguel Hidalgo y Agustín de Iturbide. Estos héroes conformaron la base sobre el que se erigió y legitimó el presidente que ocupó inmediatamente el tercer lugar de aparición en el álbum. Obregón, como Hidalgo o Iturbide, formaba parte de ese árbol genealógico nacional que era "la familia de la Patria”, familia de gran coraje que había recuperado sus tierras

\footnotetext{
${ }^{20}$ Se debe notar en el tratamiento y la organización, el cuidado del documento histórico como un recuerdo familiar que apunta, así, a la importancia de la representación y preservación de la memoria de la patria, de una nación que celebra la conmemoración de la independencia y que debe respetarse como un hecho solemne y representativo de su valor histórico.

${ }^{21} \mathrm{El}$ álbum es un libro de 37 × $25 \mathrm{~cm}$ aproximadamente, de pasta dura y de color beige que se importa de Estados Unidos. En la parte posterior de la portada hay una apostilla circular que representa a un águila sobre la bandera estadounidense con número de referencia 63342 de la American Book \& Printing Company.
} 
bajo el grito de "¡Muera el mal gobierno!” y cuyo legado se mantenía vivo. A continuación, dos páginas dedicadas a retratos de los personajes más sobresalientes del momento como Alberto J. Pani, Adolfo Best Maugard, Gerardo Murillo, Dr. Atl, De la Huerta o Estrada resaltaba a los intelectuales que manejaban las redes de poder establecidas en México en la década de 1920.

\section{FIGURA 2}

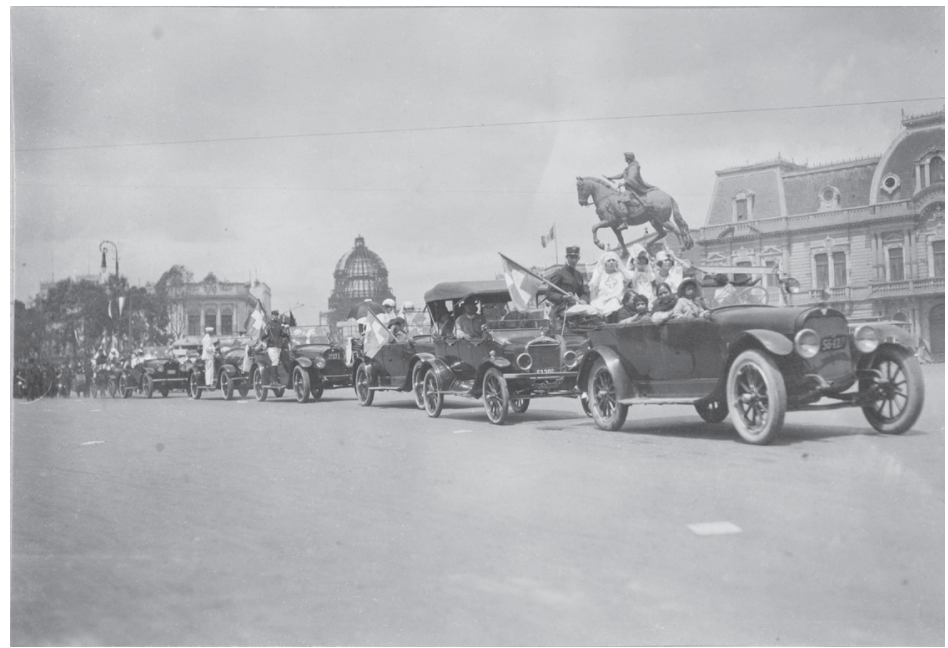

Carroza del periódico El Universal con la India Bonita, Ciudad de México, 1921.

Archivo Histórico de la Universidad Nacional Autónoma de México, Centro de Estudios sobre la Universidad, Fondo Martín Luis Guzmán, Álbum fotográfico de Martín Luis Guzmán.

Una vez legitimado el discurso, se dispuso la correlación de los distintos actos marcados para el Centenario, constituyendo un documento importantísimo para su estudio. Las cinco páginas siguientes muestran las fotografías de los delegados miembros del cuerpo diplomático de Brasil, España, Japón y Perú con sus respectivas esposas. Ahí se observa la delicadeza del tratamiento fotográfico que enaltecía a los personajes y mostraba la relevancia de sus cargos políticos. Continuó con la visita del presidente a la ciudad de Córdoba, Veracruz, donde encabezó varios actos y asistió a una recepción en su honor en la que se recreaba la firma del Tratado de Córdoba, ${ }^{22}$ la elección de la Reina

${ }^{22}$ El Tratado de Córdoba, por el que España reconoce la Independencia de México, fue firmado en la ciudad homónima el 24 de agosto de 1821 por Agustín de Iturbide -jefe de la facción independentistay por Juan O’Donojú -virrey de la Nueva España. 
de las Fiestas y el desfile de carros alegóricos fabricados por el pueblo y con temas populares. La importancia de que el presidente fuera a Córdoba fue fundamental, puesto que, según la prensa de la época, los festejos de provincia más importantes fueron los de los estados de Guanajuato y Jalisco. ${ }^{23}$ De las fotografías se planteaba la posibilidad de que el desfile histórico y el de carros alegóricos se hubiera fusionado en uno solo dando lugar a la representación de distintos momentos de la historia mexicana hasta 1921, como fue el caso de una de las fotografías que muestran el episodio de la llegada de los españoles a México en 1531, tomas sobre las que realizaban anotaciones manuscritas que otorgaban gran detalle informativo a las escenas.

\section{FIGURA 3}

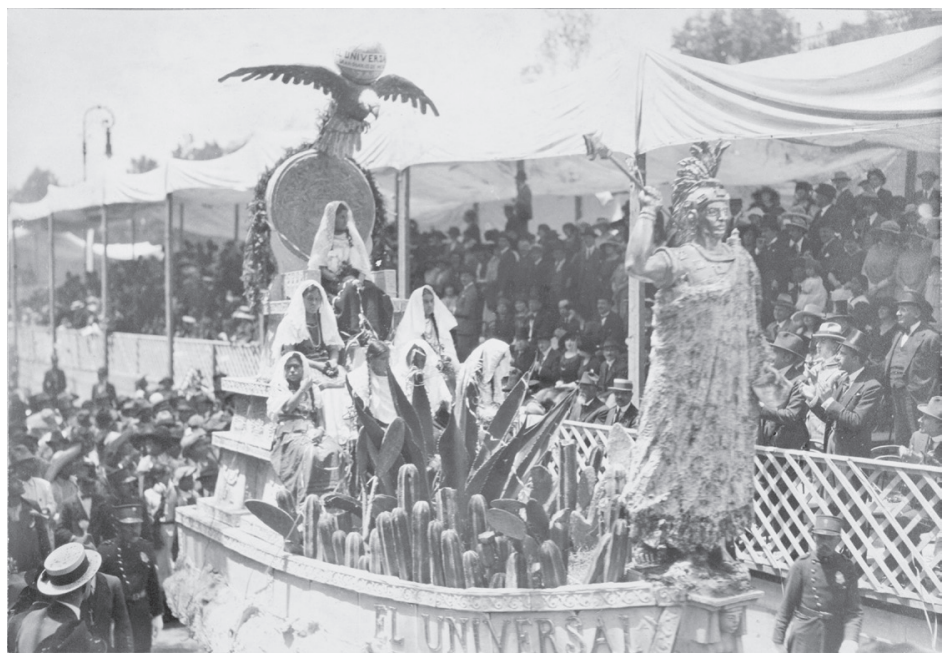

Carroza de la llegada de los españoles a México, Ciudad de México, 1921.

Archivo Histórico de la Universidad Nacional Autónoma de México, Centro de Estudios sobre la Universidad, Fondo Martín Luis Guzmán, Álbum fotográfico de Martín Luis Guzmán.

En definitiva, el álbum particular de Martín Luis Guzmán supuso un esfuerzo por registrar los festejos de Independencia en el que se destacó su carácter narrativo social, la necesidad de historiar y de hacer historia y la ausencia de referencias personales o familiares. Siguió el modelo de álbum

\footnotetext{
${ }^{23}$ Véase "Las fiestas patrias en Guadalajara", Revista de Revistas, XIII (646), México, 24 de septiembre de 1922, pp. 42-3; Rangel, Nicolás, "Guanajuato, cuna de la insurrección de 1810", Revista de Revistas, X (489), México, 14 de septiembre de 1919, p 7.
} 
oficial dando preponderancia a los homenajes, los honores a bandera y los desfiles hechos a la francesa, pero sobre todo, destacando el papel que la sociedad representó en tal celebración.

Los álbumes oficiales y el particular de Guzmán supusieron una expectativa de registro y el mejor escaparate internacional de México como un país democrático y moderno. Si bien las fiestas celebradas por el general Porfirio Díaz y el caudillo revolucionario Álvaro Obregón fueron muy distintas, ambas pretendieron ser un factor de cambio en la historia del país para promover la festividad como una herramienta para estrechar y consolidar los intercambios comerciales que se habían forjado con las potencias extranjeras. Constituyeron entonces y en la actualidad un verdadero testimonio documental y gráfico para el estudio de sus respectivas celebraciones. 
CITAM Derechos Reservados.

La reproducción total o parcial de este artículo se podrá hacer si el ITAM otorga la autorización previamente por escrito. 